\title{
Clay Swelling: Role of Cations in Stabilizing/Destabilizing Mechanisms
}

\author{
Wen L. Chen,* Robert C. Grabowski, and Saurav Goel
}

Cite This: ACS Omega 2022, 7, 3185-3191

Read Online

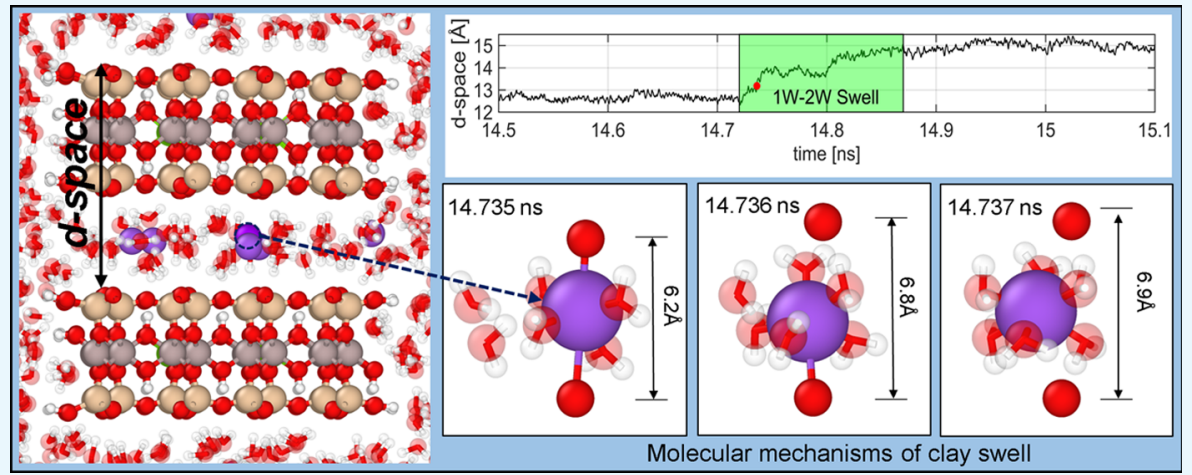

ABSTRACT: The stepwise hydration of clay minerals has been observed repeatedly in studies, but the underlying mechanism remains unclear. Previous numerical studies confirmed the presence of one-water layer (1W) and two-water layer (2W) hydration states. However, the undisturbed transition between these hydration states has never been captured. Using molecular dynamics simulation, this study (i) simulated for the first time the free $1 \mathrm{~W}-2 \mathrm{~W}$ transition during clay hydration and (ii) identified the underlying mechanism to be the detachment of cations from the clay surface and the formation of a shell of water molecules around the cation. The swelling dynamics of clay was found to be affected by the clay charge, clay mineralogy, and counterions through complex cation-clay interactions, cation hydration capacity, and cation migration rate.

\section{INTRODUCTION}

Clays, such as montmorillonite (MMT) and beidellite (BD), are important constituents of soil and have wide engineering applications, including building material, environmental remediation, catalysis, and geological disposal of nuclear waste. $^{1-4}$ MMT and BD carry negative charges in their platelike layers due to the isomorphous substitution of silicon $(\mathrm{Si})$ or aluminum $(\mathrm{Al})$ atoms with atoms of a lower valence. To balance out the charge, these substitutions are associated with positively charged cations within the interlayer space. ${ }^{5}$ In the presence of water, the interlayer cations attract water molecules, pushing clay layers apart, in a process generally described as clay hydration or clay swelling. ${ }^{6,7}$ However, questions remain on the molecular dynamics driving clay swelling, particularly related to the molecular interactions that affect the movement of cation and water molecules in the interparticle layer of expansive clays.

Clay swelling occurs in two regimes, crystalline and osmotic, depending on the $d$-space of the clay particle. The $d$-space is defined for clay particles as the sum of the interlayer distance and the thickness of one clay layer. Crystalline swelling occurs when the $d$-space increases from 10 to $22 \AA$, and osmotic swelling occurs when the $d$-space swells beyond $22 \AA^{8}{ }^{8}$ Crystalline swelling has been observed to occur in a stepwise fashion. ${ }^{9}$ The $d$-space changes abruptly from dry to a one-water layer (1W) hydration state, as well as from a one-water layer to a two-water layer (2W) hydration state. ${ }^{8-10}$ Numerical simulations have been performed to investigate aspects of the hydration process of clay. ${ }^{9-18}$ However, previous studies have either (i) inserted water molecules into the space confined by clay layers infinitely extending in horizontal directions, ${ }^{7,16,19-21}$ (ii) steered molecular dynamics by imposing extra expanding force or potential, ${ }^{12,18}$ or (iii) focused on swelling dynamics at a larger $d$-space (i.e., $18.8 \AA$ in ref 11). There remain significant gaps in our scientific understanding of (i) "free" swell from the $1 \mathrm{~W}$ to $2 \mathrm{~W}$ hydration states, in which water molecules are allowed to move freely from bulk water to the interlayer space, (ii) the underlying molecular mechanism of stepwise swelling, and (iii) the influence of clay charge, mineralogy, and interlayer cations on

Received: August 13, 2021

Accepted: December 17, 2021

Published: January 17, 2022 
the "free" swell of clays. To address these gaps, molecular dynamics simulation on the swelling of clay particles was performed in this study.

\section{MATERIALS AND METHODS}

Recent development in the CLAYFF force field allows clay particles in a molecular dynamics simulation large-scale atomic/ molecular massively parallel simulator (LAMMPS ${ }^{22}$ ) to have protonated edges. ${ }^{12,14,23,24}$ With CLAYFF, water molecules can move freely in and out of the clay particle, something that was not possible in earlier force fields. ${ }^{15,25}$ In this study, the mechanisms underlying stepwise swell were investigated using a two-layer model placed in a water box (Figure S1 in the Supporting Information). Each layer was modeled as a tetrahedral-octahedral-tetrahedral $(\mathrm{T}-\mathrm{O}-\mathrm{T})$ structure and contained eight $\mathrm{Si}_{8}\left(\mathrm{Al}_{4^{-} x} \mathrm{Mg}_{x}\right) \mathrm{O}_{20}(\mathrm{OH})_{4}$ (representing $\mathrm{MMT}$ ) or $\mathrm{Si}_{8-x} \mathrm{Al}_{4+x} \mathrm{O}_{20}(\mathrm{OH})_{4}$ (representing $\mathrm{BD}$ ) units. The $x$ substitution of $\mathrm{O}-\mathrm{Al}$ by $\mathrm{Mg}$ (magnesium) in MMT or $\mathrm{T}-\mathrm{Si}$ by $\mathrm{Al}$ in $\mathrm{BD}$ leads to $\mathrm{a}-x \mathrm{e} /$ unit cell charge. Sodium $(\mathrm{Na})$, potassium $(\mathrm{K})$, and calcium $(\mathrm{Ca})$ were chosen as counterions for their differences in valence and hydration capacity. ${ }^{26}$ The simulations were directed to test the effect of clay charge (from -0.125 to -0.75 e/unit cell), using different numbers of $\mathrm{Na}$ counterions (2, 4, 6, 8, 10, and 12 ions), and cation types ( $\mathrm{K}$ and $\mathrm{Ca}$, with 12 and 6 ions, respectively). The bottom layer was kept fixed throughout the simulation. ${ }^{13,27}$ The top layer was fixed for the first $1 \mathrm{~ns}$ of simulation to allow the system to reach equilibrium and then was allowed to move freely vertically, in which case the clay swells naturally. No other restriction was applied to the system (preparation of clay sample and model system are provided in the Supporting Information).

\section{RESULTS AND DISCUSSION}

Relaxing from an initial $d$-space of $11.9 \AA$, stable hydration states and stepwise swell were successfully reproduced for MMT (Figure 1). Stable 1W states were observed for $\mathrm{Na}$ with

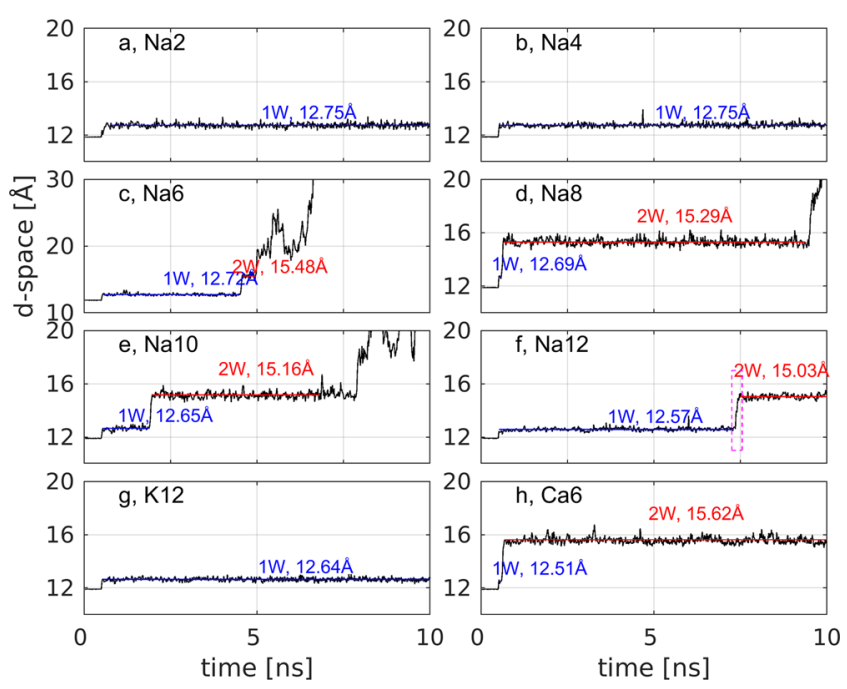

Figure 1. Hydration of MMT over time as represented by the $d$ space: (a) Na2, with two $\mathrm{Na}$ in the interlayer space, carries $-0.125 \mathrm{e} /$ unit cell; (b) Na4 carries -0.25 e/unit cell; (c) Na6 carries -0.375 e/ unit cell; (d) Na8 carries -0.5 e/unit cell; (e) Na10 carries -0.625 e/ unit cell; (f) Na12 carries -0.75 e/unit cell; (g) K12 carries -0.75 e/ unit cell; and (h) Ca6 carries -0.75 e/unit cell. two and four counterions in the interlayer space (Figure 1a,b) and for $\mathrm{K}$ with 12 counterions (Figure $1 \mathrm{~g}$ ). Stepwise swell from the $1 \mathrm{~W}$ to the $2 \mathrm{~W}$ state was observed for $\mathrm{Na}$, with 10 and 12 counterions (Figure 1e,f), and with six counterions for $\mathrm{Ca}$ (Figure $1 \mathrm{~h}$ ). There was no evidence of stable, higher hydration states. In simulations relaxed from a higher initial $d$-space, i.e., at 15.8 and $18.8 \AA$, Ca6 reached a stable $2 \mathrm{~W}$ state for both initial $d$-spaces, and Na12 reached a stable $2 \mathrm{~W}$ state at a $15.8 \AA$ initial $d$-space (Figures $S 4$ and $S 5$ in the Supporting Information). The $1 \mathrm{~W}$ hydration states of $\mathrm{Na} 8$ and $\mathrm{Ca} 6$ were very short, indicating a direct swell to the $2 \mathrm{~W}$ hydration state. Continued osmotic swelling was observed for $\mathrm{Na}$ with 6, 8 , and 10 counterions. The $1 \mathrm{~W}-2 \mathrm{~W}$ swell occurs rapidly, i.e., in less than $0.2 \mathrm{~ns}$, leading to a sudden change in the measured $d$-space, which is distinct from the continuous change in the $d$ space in osmotic swelling (i.e., in $\mathrm{Na} 6, \mathrm{Na} 8$, and $\mathrm{Na} 10$ ). The $d$ space of $1 \mathrm{~W}$ and $2 \mathrm{~W}$ hydration states agree well with the experimental observation and previous numerical studies (Figure 1). ${ }^{11,18,28-33}$ In particular, the $1 \mathrm{~W}$ and $2 \mathrm{~W} d$-space of Na12 aligns closely with prior molecular simulation studies (Figure 1f), i.e., $12.57 \AA$ for $1 \mathrm{~W}$ and $15.03 \AA$ for $2 \mathrm{~W} .{ }^{12}$ The simulations reproduce previously observed swelling behaviors of $\mathrm{Na}-\mathrm{MMT},{ }^{34}$ specifically the expansion to $2 \mathrm{~W}$ and the higher $d$-space for Na-MMT of medium and high charges (Figure 1cf).

The simulations indicate that the mechanism of crystalline swelling is the detachment and hydration of the counterions. The coordination of water oxygen $\left(\mathrm{O}_{\mathrm{w}}\right)$ with counterions was observed to begin before the abrupt increase in the $d$-space and continued during the swelling process, along with a decrease in the number of coordinated clay oxygen $\left(\mathrm{O}_{\mathrm{b}}\right.$, Figure $\left.2 \mathrm{~b}\right) . \mathrm{O}_{\mathrm{w}}$ and $\mathrm{O}_{\mathrm{b}}$ within a $3.0 \AA$ zone from the counterions were coordinated. Visualization of the atomic interactions illustrates that during crystalline swelling, the top $\mathrm{O}_{b}$ and top layer are pushed upward as the bond between $\mathrm{Na}$ and $\mathrm{O}_{b}$ breaks and a new bond between $\mathrm{Na}$ and $\mathrm{O}_{\mathrm{w}}$ forms (Figure 2a). As a result, the density profile of $\mathrm{O}_{\mathrm{w}}$ splits from one peak around $\mathrm{Na}$ at the $1 \mathrm{~W}$ state to two peaks around $\mathrm{Na}$ at the $2 \mathrm{~W}$ state (Figure $2 \mathrm{c}-$ e). Correlation analysis of the $d$-space and averaged coordinated $\mathrm{O}_{\mathrm{w}}$ and $\mathrm{O}_{\mathrm{b}}$ (i.e., the total number of coordinated $\mathrm{O}_{\mathrm{w}}$ or $\mathrm{O}_{\mathrm{b}}$ divided by the number of interlayer cations), collected at the $1 \mathrm{~W}-2 \mathrm{~W}$ transition, confirms the high correlation between these data sets (Figure 3). A shell of four $\mathrm{O}_{\mathrm{w}}$ and two $\mathrm{O}_{\mathrm{b}}$ surrounds a single $\mathrm{Na}$ at the $1 \mathrm{~W}$ state and a shell of six $\mathrm{O}_{\mathrm{w}}$ at the $2 \mathrm{~W}$ state. The same correlation was found for the $1 \mathrm{~W}-2 \mathrm{~W}$ transition for $\mathrm{Na} 6, \mathrm{Na} 8, \mathrm{Na} 10$, and $\mathrm{Ca} 6$ (not presented here), which supports previous studies reporting the influence of interlayer cation hydration on the crystalline swelling of clay. ${ }^{6,15,17,19}$

While the hydration of counterions is the mechanism generating crystalline swelling, the counterions are still responsible for the dominant attractive force stabilizing the $1 \mathrm{~W}$ and $2 \mathrm{~W}$ hydration states. An analysis of the force imposed on the top clay layer identifies an attractive force $\left(F_{\mathrm{TC}}<0\right)$ from the interlayer cations, which has a greater magnitude than the repulsive force from the bottom layer $\left(F_{\mathrm{TB}}>0\right.$ and $\left|F_{\mathrm{TC}}\right|>1$ $\left.F_{\mathrm{TB}} \mathrm{I}\right)$ (Figure $\left.4 \mathrm{a}, \mathrm{b}\right)$. A third force stems from the interaction between the top clay layer and the surrounding water molecules, which can be either repulsive or attractive depending on their relative location. The water molecules within the interlayer space, however, always provide a strong repulsive force on the top clay layer $\left(F_{\mathrm{TW}}>0\right.$, Figure $\left.4 \mathrm{a}, \mathrm{b}\right)$. In the process of $1 \mathrm{~W}-2 \mathrm{~W}$ swell, water molecules are attracted to 

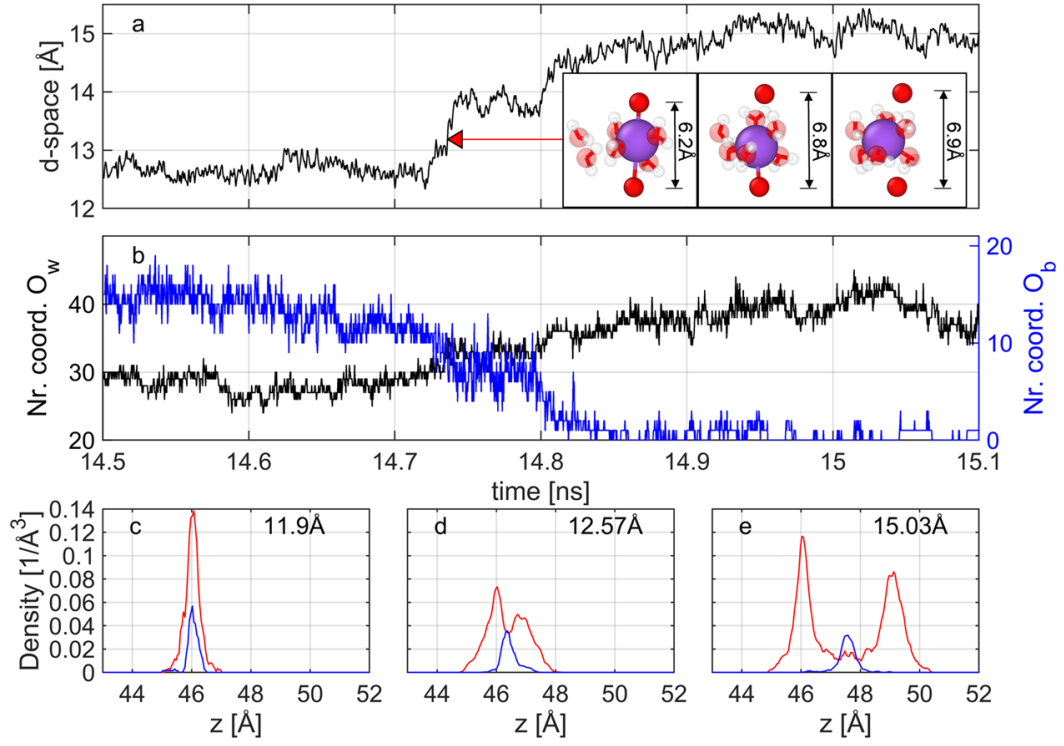

Figure 2. Detailed $1 \mathrm{~W}-2 \mathrm{~W}$ swell process of Na12 (the magenta rectangle in Figure 1f): (a) the evolution of $d$-space and (b) the evolution of coordinated $\mathrm{O}_{\mathrm{w}}$ (black curve) and $\mathrm{O}_{\mathrm{b}}$ (blue curve) number. Distribution of $\mathrm{O}_{\mathrm{w}}$ (red curve) and $\mathrm{Na}$ (blue curve) within the interlayer space at the $d$ space of (c) $11.9 \AA$, (d) $12.57 \AA$ (1W), and (e) $15.03 \AA$ (2W) are present. The slightly lower peaks at a higher $z$ position in d and e are due to the fluctuation of the top layer.
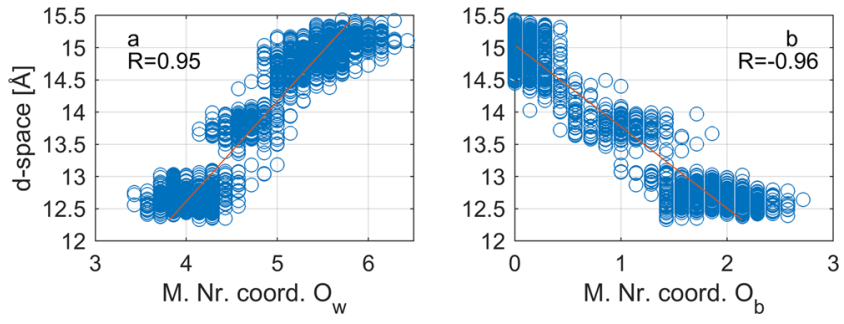

Figure 3. Correlation between the $d$-space and the average number of coordinated $\mathrm{O}_{\mathrm{w}}(\mathrm{a})$ and $\mathrm{O}_{\mathrm{b}}(\mathrm{b})$ for each cation for MMT.

coordinate with the interlayer cations. As a result, $F_{\mathrm{TW}}$ continuously increases and pushes up the top clay layer (Figure S2 in the Supporting Information). The decomposition of these forces shows that in the first two forces, the Coulombic interaction dominates over pairwise interactions, whereas in the third force, only pairwise interactions are involved (Figure S3 in the Supporting Information). The swelling state of clay particles depends on the competition between these three contributions.

Clay with a higher negative charge (i.e., a greater number of substitutions) experiences a stronger repulsive/attractive force from the bottom clay/cation, but it also experiences a stronger repulsive force from the hydration of interlayer $\mathrm{Na}$ (Figure 4a). The full hydration of $\mathrm{Na}$ attracted six $\mathrm{O}_{\mathrm{w}}$ to form a shell surrounding one single $\mathrm{Na}$ (Figure 3). The strong repulsive force exerted on the top layer in this process is indicated by the number of missing coordinated $\mathrm{O}_{w}$. At the $1 \mathrm{~W}$ hydration state, the repulsive force increases for the clay of a higher negative charge (Figure $4 \mathrm{c}$ ) as more interlayer $\mathrm{Na}$ attracts water and becomes fully hydrated. As a result, the equilibrium state of the $\mathrm{Na} 6, \mathrm{Na} 8, \mathrm{Na} 10$, and $\mathrm{Na} 12$ swelled beyond the $1 \mathrm{~W}$ hydration state. A smaller 1W $d$-space was observed for the clay of a higher negative charge (Figure 1), which agrees with the experimental observation and is due to a stronger clay-cation attraction. ${ }^{35}$ At the $2 \mathrm{~W}$ state, the stronger clay-cation interaction in the Na12 constrained a $2 \mathrm{~W}$ state (Figure 5), whereas $\mathrm{Na} 6, \mathrm{Na} 8$, and $\mathrm{Na} 10$ continued to swell. For Na10, the diffusion of $\mathrm{Na}$ from the interlayer region to bulk water leads to weaker constraining forces from the cation to both top and bottom clay layers (Figure $5 a-c$ ), which, in turn, reduces the resistance to the migration of water molecules into the interlayer region (i.e., driven by the osmotic pressure) and the osmotic swelling of clay. Alternatively, the stronger force and interaction between clay and cation in $\mathrm{Na} 12$ restrains $\mathrm{Na}$ from moving out of the interlayer region and prevents osmotic swelling, as suggested by previous experimental studies. ${ }^{26}$ The various hydration states of medium-charged clay and highcharged clay result from the competition between osmotic pressure and cation-clay interaction, which requires further molecular dynamic studies to verify.

In addition to the hydration capacity of the cation, the swelling behavior of Na-, K-, and Ca-MMT varies due to the mobility of the counterion in the interlayer space. The number of coordinated $\mathrm{O}_{\mathrm{w}}$ attracted to the cations at its $1 \mathrm{~W}$ state differs between $\mathrm{Ca}, \mathrm{Na}$, and $\mathrm{K}$ (Figure $4 \mathrm{~d}$ ), indicating a decreasing hydration capacity. ${ }^{17}$ This behavior is supported by the radial distribution function of cations and $\mathrm{O}_{\mathrm{w}}$ (Figure $4 \mathrm{~g}$ ). $\mathrm{Ca}$ had the greatest density of coordinated $\mathrm{O}_{\mathrm{w}}$, with $\mathrm{K}$ having the lowest and $\mathrm{Na}$ having an intermediate density of coordinated $\mathrm{O}_{\mathrm{w}}$. The migration of cations (depending on the type of cation) within the interlayer space is greatly inhibited by the clay (Figure 4e,f). Among these cations, the inhibition effect is strongest on $\mathrm{K}$, as its migration rate drops most from the bulk water environment to the interlayer space. ${ }^{36}$ As a combined result of weak hydration capacity and strong inhibition on migration, K-MMT had the most stable 1W hydration state (Figure $1 \mathrm{~g}$ ). ${ }^{33}$ The strong hydration capacity of Ca led to a quick swell of Ca-MMT to the $2 \mathrm{~W}$ state (Figure $1 \mathrm{~h}$ ), whereas its low migration rate prevented it from swelling to higher $d$-space (Figure S4 and 5c). ${ }^{19}$ The intermediate hydration capacity of $\mathrm{Na}$ led to the slow $1 \mathrm{~W}-2 \mathrm{~W}$ transition of Na12 (Figure 1f), but at a higher $d$-space, the stabilizing effect of $\mathrm{Na}$ was weakened by its fast migration rate (i.e., osmotic swelling of Na12 when relaxed from $18.8 \AA$ ). 

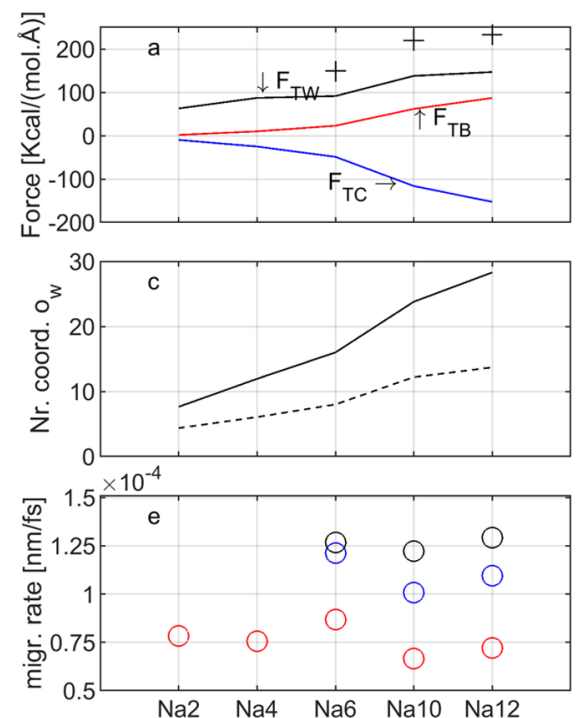
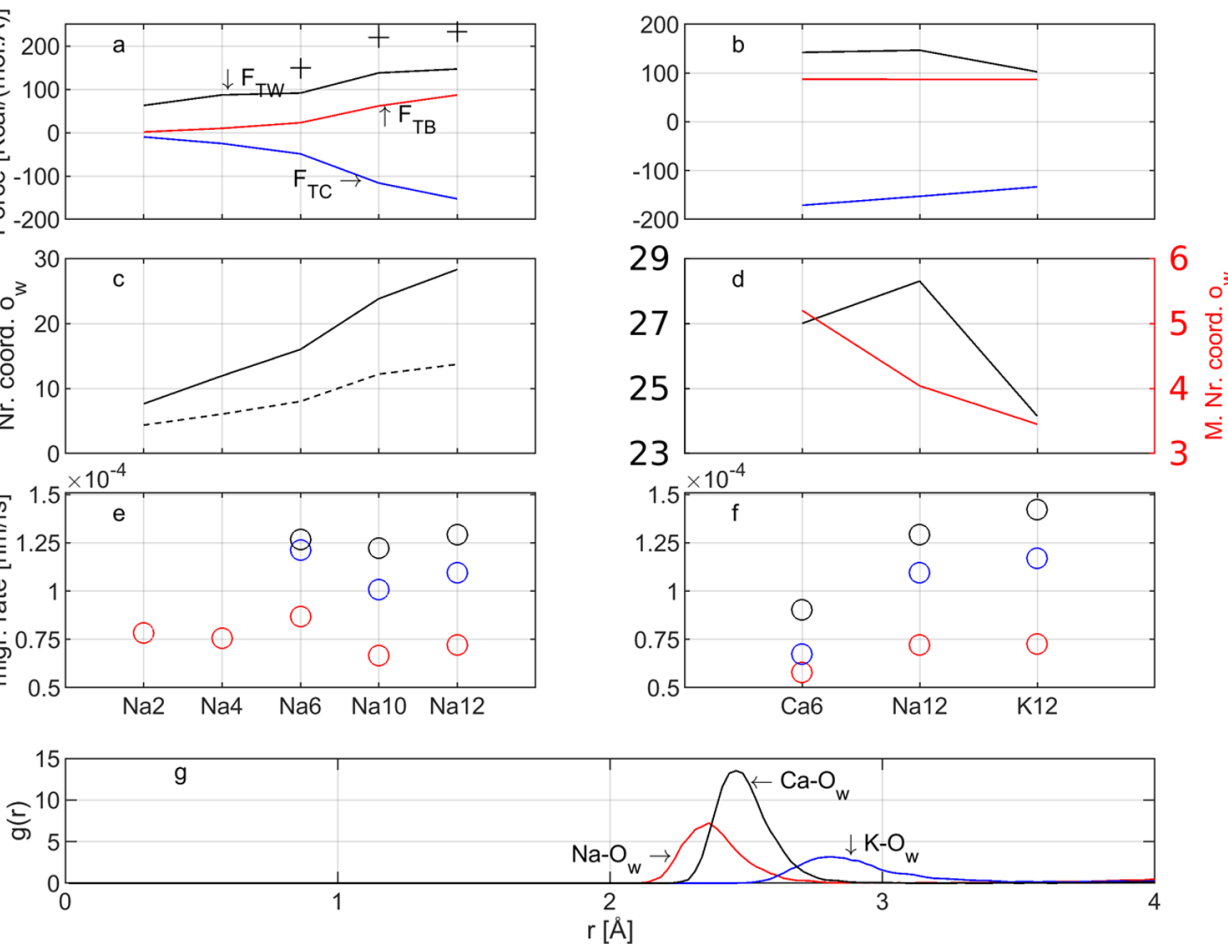

Figure 4. Force analysis showing (a) forces on the top clay layer for Na-MMT with various clay charges (black crosses stand for $F_{\mathrm{TW}}$ at the $2 \mathrm{~W}$ state, and negative/positive value indicates an attractive/repulsive force on the top layer); (b) forces on the top layer for Ca-, Na-, and K-MMT with 6,12, and 12 counterions, respectively; (c) total coordinated $\mathrm{O}_{\mathrm{w}}$ for interlayer $\mathrm{Na}$ (black dashed curve indicates the missing number of $\mathrm{O}_{\mathrm{w}}$ to be attracted if all $\mathrm{Na}$ are fully hydrated); (d) total (black) and mean (red) number of coordinated $\mathrm{O}_{\mathrm{w}}$ for $\mathrm{Ca}, \mathrm{Na}$, and $\mathrm{K}$ extracted at the $1 \mathrm{~W}$ hydration state; (e) migration rates of interlayer $\mathrm{Na}$, with red, blue, and black color distinguishing cation in the interlayer region, $1 \mathrm{~nm}$ away from clay and bulk water; (f) migration rates for interlayer $\mathrm{Na}, \mathrm{Ca}$, and $\mathrm{K} ;(\mathrm{g})$ the radial distribution function of cation and $\mathrm{O}_{\mathrm{w}}$. All results presented were extracted from $1 \mathrm{~W}$ hydration states unless specified.
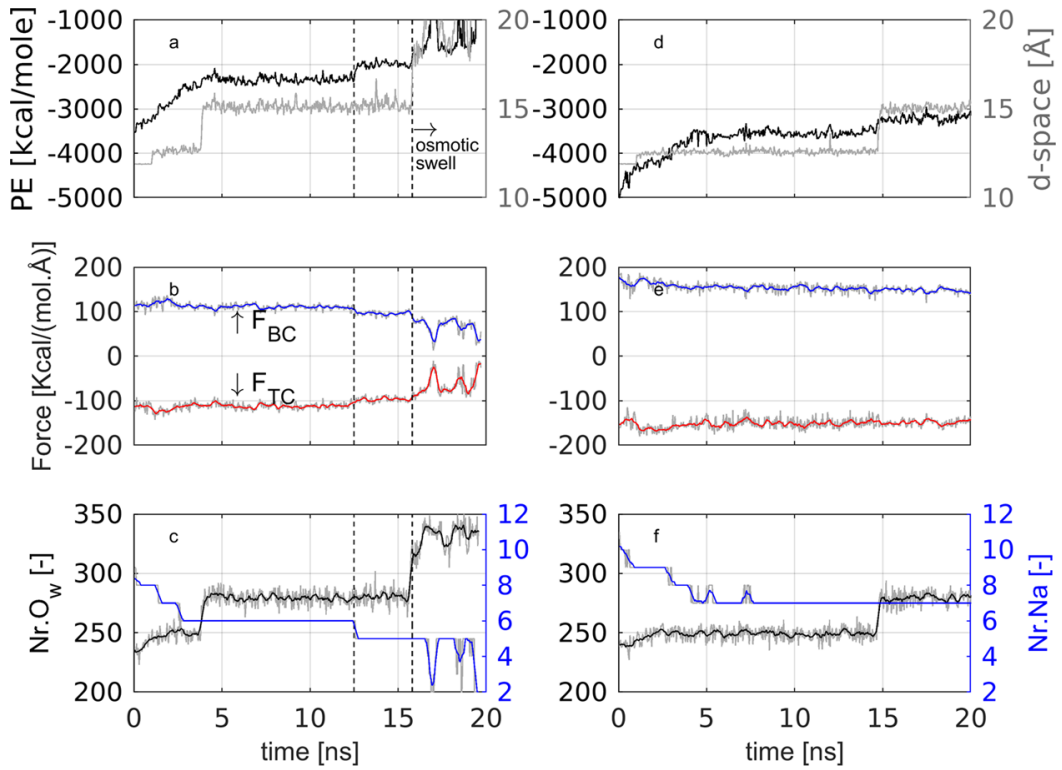

Figure 5. Comparison of swelling for Na10 $(a-c)$ and Na12 $(d-f)$ showing $(a)$ the interaction energy of clay and interlayer cation (black) and swelling curve (gray); (b) forces from interlayer cation onto the top clay layer $\left(F_{\mathrm{TC}}\right.$, red) and the bottom clay layer $\left(F_{\mathrm{BC}}\right.$, blue); $(\mathrm{c})$ number of interlayer $\mathrm{O}_{\mathrm{w}}$ (black) and $\mathrm{Na}$ (blue).

The hydration of Na-BD relaxed from $11.9 \AA$-space and reached stable $1 \mathrm{~W}$ states for all charges (Figure 6a-d). The $1 \mathrm{~W} d$-spaces of $\mathrm{BD}$ (i.e., 13.04 and $13.1 \AA$ for $\mathrm{BD}-\mathrm{Na} 4$ and $\mathrm{BD}$ $\mathrm{Na12}$, respectively, Figure 6) were larger than those of MMT (i.e., 12.75 and $12.57 \AA$ for $\mathrm{Na} 4$ and Na12, respectively, Figure $1)$. In contrast, the $2 \mathrm{~W} d$-spaces of $\mathrm{BD}$ generated with a higher initial $d$-space were smaller, i.e., around 14.3 $\AA$ for BD (Figures S4 and 5d,e) compared with more than $15.0 \AA$ for MMT (Figures $1 \mathrm{c}-\mathrm{f}, \mathrm{S} 4$, and $5 \mathrm{a}-\mathrm{c}$ ). This reverse in the trend has also been observed by a previous modeling study ${ }^{15}$ and supported by experimental work. ${ }^{37}$ Compared to MMT, $F_{\mathrm{TB}}$ and $F_{\mathrm{TC}}$ were stronger in $\mathrm{BD}$ and the interlayer $\mathrm{Na}$ migration 

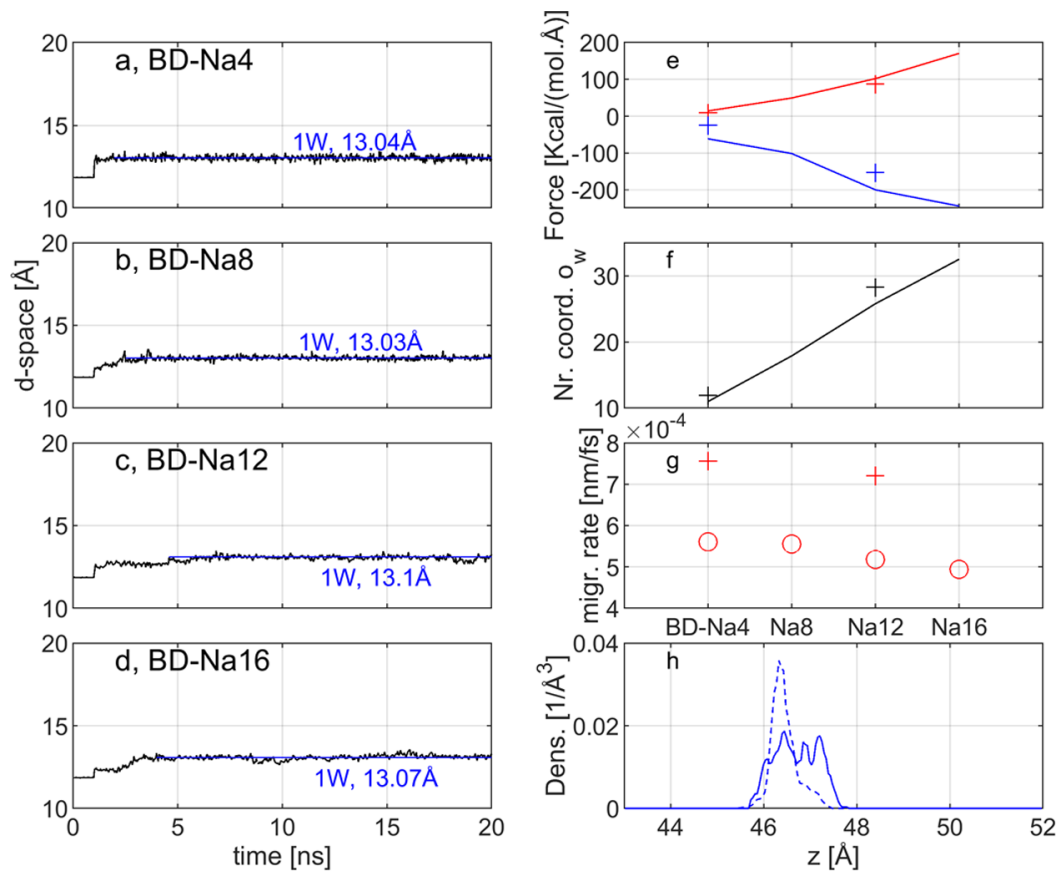

Figure 6. Swelling of BD showing (a) the swelling curve of BD-Na4, with four Na as counterions, carries -0.25 e/unit cell charge; (b) swelling curve of BD-Na8 carries -0.5 e/unit cell; (c) swelling curve of BD-Na12 carries -0.75 e/unit cell; and (d) swelling curve of BD-Na16 carries - 1.0 e/unit cell; (e) forces on top clay for $F_{\mathrm{TB}}$ (red) and $F_{\mathrm{TC}}$ (blue); (f) number of coordinated interlayer $\mathrm{O}_{w}$; $(\mathrm{g})$ migration rate of interlayer Na; (h) density profile of interlayer Na for Na12 in BD (solid) and MMT (dashed). Crosses in (e), (f), and (g) are values for MMT.

rate was lower (Figure 6f), which is due to the shift from the central negative charge in MMT (as $\mathrm{O}-\mathrm{Al}$ replaced by $\mathrm{Mg}$ ) to a surface-negative charge in $\mathrm{BD}$ (as $\mathrm{T}-\mathrm{Si}$ replaced by $\mathrm{Al}$ ). The interlayer $\mathrm{Na}$ density profile of $\mathrm{BD}$ was flat and loosely split into two peaks, in contrast to a single peak profile in MMT, indicating that $\mathrm{Na}$ in $\mathrm{BD}$ is more attracted to the clay surface (Figure $6 \mathrm{~h}$ ). $\mathrm{BD}$ with $12 \mathrm{~K}$ and six $\mathrm{Ca}$ as counterions also stabilizes at $1 \mathrm{~W}$ states (Figure S4).

In this study, free swell was investigated from the $1 \mathrm{~W}$ hydration state, not $0 \mathrm{~W}$, because of the presence of an energy barrier for the $0 \mathrm{~W}-1 \mathrm{~W}$ swell. ${ }^{12,18}$ At the $1 \mathrm{~W}$ state and a higher $d$-space, the protonated clay edge permits the diffusion of water molecules and cations, but, at the $0 \mathrm{~W}$ state, exposed $-\mathrm{OH}$ groups form hydrogen bonds in between adjacent layers. According to Ho et al., ${ }^{12}$ these hydrogen bonds act like a gate preventing the inflow of water molecules into the interlayer space and impose an energy barrier for 0W-1W swell. Consequently, simulation with the current CLAYFF is not able to simulate the $0 \mathrm{~W}-1 \mathrm{~W}$ swell. Fixing the bottom layer and controlling the direction of the swell have been used to estimate the osmotic swelling pressure of clay ${ }^{13,27}$ and are first used to investigate the free $1 \mathrm{~W}-2 \mathrm{~W}$ swell in this study. It is a stepwise improvement in the modeling. Future modeling should consider the lateral movement of the clay layers and the breakdown or misorientation of clay platelets in the swelling process, which has been observed in the swelling experiment and is found to affect the interlayer water content. ${ }^{38}$

\section{CONCLUSIONS}

Using a molecular dynamics approach, this study simulated the free expansion of clay layers during hydration and identified the key mechanisms for the stepwise swell from the $1 \mathrm{~W}$ to the $2 \mathrm{~W}$ hydration state. Crystalline swelling is triggered by the detachment of cations from the clay surface and the formation of a shell of water molecules around the cations in the interlayer space. The full hydration of cations causes the clay to swell from the $1 \mathrm{~W}$ to the $2 \mathrm{~W}$ hydration state, but it also generates the attractive force that stabilizes both states through clay-cation Coulombic attraction. Importantly, the swelling dynamics of clay is affected by the clay charge, clay mineralogy, and counterions through complex cation-clay interactions, cation hydration capacity, and cation migration rate. Future work should investigate the chemistry and interactions of the surrounding water with the counterion and its effect on clay swelling.

\section{ASSOCIATED CONTENT}

\section{(I) Supporting Information}

The Supporting Information is available free of charge at https://pubs.acs.org/doi/10.1021/acsomega.1c04384.

Full computation methods and details on the hydration of Montmorillonite and Beidellite (PDF)

\section{AUTHOR INFORMATION}

\section{Corresponding Author}

Wen L. Chen - School of Water, Energy and Environment, Cranfield University, Cranfield, Bedfordshire MK43 OAL, U.K.; ○ orcid.org/0000-0002-2146-8011; Email: wenlong.chen@cranfield.ac.uk

\section{Authors}

Robert C. Grabowski - School of Water, Energy and Environment, Cranfield University, Cranfield, Bedfordshire MK43 OAL, U.K.

Saurav Goel - London South Bank University, London SE1 OAA, U.K.; Shiv Nadar University, Greater Noida 201314, India; Indian Institute of Technology Guwahati, Guwahati 781039, India; University of Petroleum and Energy Studies, 
Dehradun 248007, India; (1) orcid.org/0000-0002-8694$332 \mathrm{X}$

Complete contact information is available at: https://pubs.acs.org/10.1021/acsomega.1c04384

\section{Notes}

The authors declare no competing financial interest. Data supporting this research is available at DOI: https:// doi.org/10.17862/cranfield.rd.15049314.v1.

\section{ACKNOWLEDGMENTS}

This work was supported primarily by the Engineering and Physical Science Research Council (Grant number EP/ T001100/1). S.G. also acknowledges support from other EPSRC grants (EP/L016567/1, EP/S013652/1, EP/ S036180/1, and EP/T024607/1), the Royal Academy of Engineering via Grant Nos. IAPP18-19\295, TSP1332, and EXPP2021 \1\277, EURAMET EMPIR A185 (2018), EU Cost Action (CA15102, CA18125, CA18224, and CA16235), Newton Fellowship award from the Royal Society (NIF $\backslash R 1 \backslash 191571)$, and the European Regional Development Funds (ERDF) sponsored A2i project at LSBU that have catalyzed several industrial partnerships. The research made use of Isambard Bristol, UK, supercomputing service accessed by Resource Allocation Panel (RAP) grant as well as ARCHER2 resources (Project e648).

\section{REFERENCES}

(1) Amato, I. Green Cement: Concrete Solutions. Nature 2013, 494, 300-301.

(2) Carretero, M. I.; Pozo, M. Clay and Non-Clay Minerals in the Pharmaceutical and Cosmetic Industries Part II. Active Ingredients. Appl. Clay Sci. 2010, 47, 171-181.

(3) Carretero, M. I. Clay Minerals and Their Beneficial Effects upon Human Health. A Review. Appl. Clay Sci. 2002, 21, 155-163.

(4) Wu, L. M.; Zhou, C. H.; Keeling, J.; Tong, D. S.; Yu, W. H. Towards an Understanding of the Role of Clay Minerals in Crude Oil Formation, Migration and Accumulation. Earth-Sci. Rev. 2012, 115, 373-386.

(5) Suter, J. L.; Anderson, R. L.; Greenwell, H. C.; Coveney, P. V. Recent Advances in Large-Scale Atomistic and Coarse-Grained Molecular Dynamics Simulation of Clay Minerals. J. Mater. Chem. 2009, 19, 2482-2493.

(6) Zhou, Z. Construction and Application of Clay-Swelling Diagrams by Use of XRD Methods. J. Pet. Technol. 1995, 47, 306.

(7) Hensen, E. J. M.; Smit, B. Why Clays Swell. J. Phys. Chem. B 2002, 106, 12664-12667.

(8) Rao, S. M.; Thyagaraj, T.; Rao, P. R. Crystalline and Osmotic Swelling of an Expansive Clay Inundated with Sodium Chloride Solutions. Geotech. Geol. Eng. 2013, 31, 1399-1404.

(9) Meleshyn, A.; Bunnenberg, C. The Gap between Crystalline and Osmotic Swelling of Na-Montmorillonite: A Monte Carlo Study. J. Chem. Phys. 2005, 122, No. 034705.

(10) Chávez-Páez, M.; de Pablo, L.; de Pablo, J. J. Monte Carlo Simulations of $\mathrm{Ca}-$ Montmorillonite Hydrates. J. Chem. Phys. 2001, 114, 10948-10953.

(11) Hsiao, Y.-W.; Hedström, M. Swelling Pressure in Systems with Na-Montmorillonite and Neutral Surfaces: A Molecular Dynamics Study. J. Phys. Chem. C 2017, 121, 26414-26423.

(12) Ho, T. A.; Criscenti, L. J.; Greathouse, J. A. Revealing Transition States during the Hydration of Clay Minerals. J. Phys. Chem. Lett. 2019, 10, 3704-3709.

(13) Sun, L.; Hirvi, J. T.; Schatz, T.; Kasa, S.; Pakkanen, T. A. Estimation of Montmorillonite Swelling Pressure: A Molecular Dynamics Approach. J. Phys. Chem. C 2015, 119, 19863-19868.
(14) Cygan, R. T.; Greathouse, J. A.; Heinz, H.; Kalinichev, A. G. Molecular Models and Simulations of Layered Materials. J. Mater. Chem. 2009, 19, 2470-2481.

(15) Teich-McGoldrick, S. L.; Greathouse, J. A.; Jové-Colón, C. F.; Cygan, R. T. Swelling Properties of Montmorillonite and Beidellite Clay Minerals from Molecular Simulation: Comparison of Temperature, Interlayer Cation, and Charge Location Effects. J. Phys. Chem. C 2015, 119, 20880-20891.

(16) Segad, M.; Jönsson, B.; Åkesson, T.; Cabane, B. Ca/Na Montmorillonite: Structure, Forces and Swelling Properties. Langmuir 2010, 26, 5782-5790.

(17) Rahromostaqim, M.; Sahimi, M. Molecular Dynamics Simulation of Hydration and Swelling of Mixed-Layer Clays. J. Phys. Chem. C 2018, 122, 14631-14639.

(18) Shen, X.; Bourg, I. C. Molecular Dynamics Simulations of the Colloidal Interaction between Smectite Clay Nanoparticles in Liquid Water. J. Colloid Interface Sci. 2021, 584, 610-621.

(19) Zhang, L.; Lu, X.; Liu, X.; Zhou, J.; Zhou, H. Hydration and Mobility of Interlayer Ions of (Nax, Cay)-Montmorillonite: A Molecular Dynamics Study. J. Phys. Chem. C 2014, 118, 2981129821.

(20) Yang, Y.; Nair, A. K. N.; Sun, S. Layer Charge Effects on Adsorption and Diffusion of Water and Ions in Interlayers and on External Surfaces of Montmorillonite. ACS Earth Space Chem. 2019, 3, 2635-2645.

(21) Li, Y.; Narayanan Nair, A. K.; Kadoura, A.; Yang, Y.; Sun, S. Molecular Simulation Study of Montmorillonite in Contact with Water. Ind. Eng. Chem. Res. 2019, 58, 1396-1403.

(22) Plimpton, S. Fast Parallel Algorithms for Short-Range Molecular Dynamics. J. Comput. Phys. 1995, 117, 1-19.

(23) Pouvreau, M.; Greathouse, J. A.; Cygan, R. T.; Kalinichev, A. G. Structure of Hydrated Kaolinite Edge Surfaces: DFT Results and Further Development of the ClayFF Classical Force Field with MetalO-H Angle Bending Terms. J. Phys. Chem. C 2019, 123, 1162811638.

(24) Pouvreau, M.; Greathouse, J. A.; Cygan, R. T.; Kalinichev, A. G. Structure of Hydrated Gibbsite and Brucite Edge Surfaces: DFT Results and Further Development of the ClayFF Classical Force Field with Metal-O-H Angle Bending Terms. J. Phys. Chem. C 2017, 121, 14757-14771.

(25) Meleshyn, A.; Bunnenberg, C. Swelling of Na/Mg-Montmorillonites and Hydration of Interlayer Cations: A Monte Carlo Study. J. Chem. Phys. 2005, 123, No. 074706.

(26) Tester, C. C.; Aloni, S.; Gilbert, B.; Banfield, J. F. Short- and Long-Range Attractive Forces That Influence the Structure of Montmorillonite Osmotic Hydrates. Langmuir 2016, 32, 1203912046.

(27) Akinwunmi, B.; Hirvi, J. T.; Kasa, S.; Pakkanen, T. A. Swelling Pressure of Na- and Ca-Montmorillonites in Saline Environments: A Molecular Dynamics Study. Chem. Phys. 2020, 528, No. 110511.

(28) Saiyouri, N.; Tessier, D.; Hicher, P. Y. Experimental Study of Swelling in Unsaturated Compacted Clays. Clay Miner. 2004, 39, 469-479.

(29) Rotenberg, B.; Morel, J.-P.; Marry, V.; Turq, P.; MorelDesrosiers, N. On the Driving Force of Cation Exchange in Clays: Insights from Combined Microcalorimetry Experiments and Molecular Simulation. Geochim. Cosmochim. Acta 2009, 73, 4034-4044.

(30) Skipper, N. T.; Sposito, G.; Chang, F.-R. C. Monte Carlo Simulation of Interlayer Molecular Structure in Swelling Clay Minerals. 2. Monolayer Hydrates. Clays Clay Miner. 1995, 43, 294303.

(31) Norrish, K. Crystalline Swelling of Montmorillonite: Manner of Swelling of Montmorillonite. Nature 1954, 173, 256-257.

(32) Yamada, H.; Nakazawa, H.; Hashizume, H.; Shimomura, S.; Watanabe, T. Hydration Behavior of Na-Smectite Crystals Synthesized at High Pressure and High Temperature. Clays Clay Miner. 1994, 42, 77-80. 
(33) Anderson, R. L.; Ratcliffe, I.; Greenwell, H. C.; Williams, P. A.; Cliffe, S.; Coveney, P.V. Clay Swelling - A Challenge in the Oilfield. Earth-Sci. Rev. 2010, 98, 201-216.

(34) Morrow, C. P.; Yazaydin, A. Ö.; Krishnan, M.; Bowers, G. M.; Kalinichev, A. G.; Kirkpatrick, R. J. Structure, Energetics, and Dynamics of Smectite Clay Interlayer Hydration: Molecular Dynamics and Metadynamics Investigation of Na-Hectorite. J. Phys. Chem. C 2013, 117, 5172-5187.

(35) Ferrage, E.; Lanson, B.; Sakharov, B. A.; Geoffroy, N.; Jacquot, E.; Drits, V. A. Investigation of Dioctahedral Smectite Hydration Properties by Modeling of X-Ray Diffraction Profiles: Influence of Layer Charge and Charge Location. Am. Mineral 2007, 92, 17311743.

(36) Suter, J. L.; Coveney, P. V.; Anderson, R. L.; Greenwell, H. C.; Cliffe, S. Rule Based Design of Clay-Swelling Inhibitors. Energy Environ. Sci. 2011, 4, 4572-4586.

(37) Makaremi, M.; Jordan, K. D.; Guthrie, G. D.; Myshakin, E. M. Multiphase Monte Carlo and Molecular Dynamics Simulations of Water and $\mathrm{CO} 2$ Intercalation in Montmorillonite and Beidellite. $J$. Phys. Chem. C 2015, 119, 15112-15124.

(38) Uddin, F. Clays, Nanoclays, and Montmorillonite Minerals. Metall. Mater. Trans. A 2008, 39, 2804-2814.

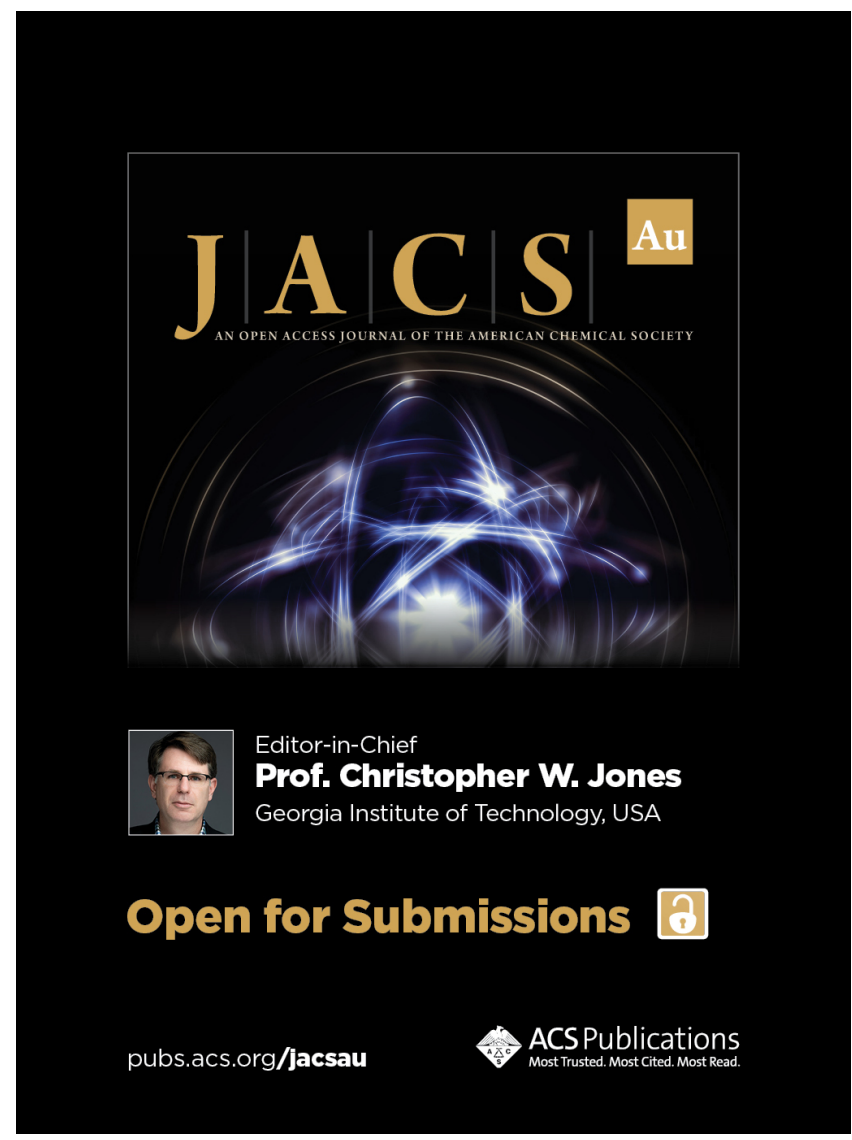

